\title{
Penyuluhan Masyarakat Tentang Masalah Emisi Gas Rumah Kaca akibat Pencemaran Sampah di Dusun V Sumbul Lestari, Desa Sumbul, Kecamatan STM Hilir, Kabupaten Deli Serdang
}

\section{Community Extension About the Greenhouse Gas Emission Problem Due to Waste Pollution in Sumbul Lestari Village, Sumbul Village, STM Hilir Sub-district, Deli Serdang District}

\author{
Mindo Tua Siagian*1, Evawani Martalena Silitonga ${ }^{2}$, Santo Damerius Silitonga ${ }^{3}$ \\ ${ }^{1}$ Sari Mutiara University, Jalan Setia Budi, Kota Medan, 20132, Indonesia \\ ${ }^{2}$ Sari Mutiara University, Jalan Irigasi V, Kota Medan, 20142, Indonesia \\ ${ }^{3}$ Sari Mutiara University, Jalan Sisingamangaraja, Kota Medan, 20216, Indonesia \\ Koresponding Penulis: ${ }^{1}$ siagianmindotua@ gmail.com, ${ }^{2}$ evawani.martalena@ gmail.com, ${ }^{3}$ silitongasanto@yahoo.com,
}

\begin{abstract}
Abstrak
Perlu kita sadari, menjaga kesehatan udara agar tetap bersih dan sehat harus dimulai dari tingkatan masyarakat terendah seperti masyarakat di daerah dusun. Dimana masyarakat di daerah dusun memiliki peranan yang sangat penting dalam menjaga kebersihan udara baik dan kesehatan secara umumnya. Permasalahan udara terhadap kesehatan seperti Infeksi Saluran Pernapasan Akut (ISPA) seperti asma, bronkitis, dan bahkan kanker paru - paru adalah banyak dari permasalahan yang ditimbulkan oleh udara yang kotor. Diperlukan kegiatan penyuluhan kepada masyarakat agar dapat mengerti dampak dari pola sehari - hari mereka dalam mengolah sampah. Metode kegiatan yang dipakai dalam kegiatan pengabdian masyarakat ini meliputi, penyuluhan secara langsung.
\end{abstract}

Kata kunci: Pendidikan masyarakat, polusi sampah, gas rumah kaca

\begin{abstract}
We need to realize, maintaining air condition to stay clean and healthy must start from the lowest level of society such as people in the village. It is happened because the community in the hamlet area has a very important role in maintaining good air cleanliness and general health. Health air problems such as acute respiratory infections (ARI) such as asthma, bronchitis and even lung cancer are many of the problems caused by dirty air. Counseling activities are needed for the community to understand the impact of their daily patterns in processing waste. The method of activities used in community service activities include, direct counseling.
\end{abstract}

Keywords: Community Education, Waste Pollution, Greenhouse Gases 
Journal of Healthcare Technology and Medicine Vol. 5 No. 2 Oktober 2019

Universitas Ubudiyah Indonesia

e-ISSN : 2615-109X

\section{PENDAHULUAN}

Berbagai macam metode telah dibuat untuk mengurangi dampak dari permasalahan udara ini seperti pembangunan tempat sampah umum di kota - kota besar. Akan tetapi sering kita lupa bahwa pentingnya menjaga kebersihan udara harus disosialisakan mulai dari kelompok terkecil masyarakat dengan pendekatan secara personal langsung kepada masyarakat. Kebiasaan menjaga kebersihan udara sangat penting untuk disalurkan kepada masyarakat terutama dari kelompok kelompok masyarakat kecil seperti dusun. Mengelola sampah dengan baik dan benar memegang peranan penting dalam menjaga kesehatan udara dan juga akan memberikan pengaruh kepada keluarga dan juga masyarakat secara luas. Karena tidak akan ada artinya mempunyai banyak tempat sampah umum di kota - kota besar apabila masyarakatnya di daerah dusun tetap mengelola sampah dengan cara yang tidak benar. Didalam penyuluhan ini selain memberikan pengertian tentang masalah - masalah yang didapat dengan mengelola sampah sembarangan terhadap pencemaran udara. Selain itu diberikan juga beberapa solusi yang dapat dibuat oleh pemerintah setempat untuk mendukung kebersihan udara di dusun tersebut.

\section{Analisis Permasalahan}

A. Mayoritas penduduk yang memerlukan pendekatan secara personal untuk menjelaskan tentang berbahayanya mengelola sampah yang tidak benar yang dapat menimbulkan pencemaran udara.

B. Mayoritas penduduk yang mengelola sampah rumah tangga maupun sampah umum nya dengan cara membakar sampah.

C. Penduduk belum memiliki kelengkapan pembuangan sampah yang mendukung kebersihan lingkungan.

D. Sampah rumah tangga yang pada umumnya memiliki bahan-bahan yang mengandung plastik dan atau zat - zat yang susah terurai lainnya yang dihasilkan dari perumahan dapat menimbulkan pencemaran udara seperti menimbulkan bau tidak enak dan juga bahkan membakar yang menyebarkan zat - zat yang dapat berdampak buruk untuk kesehatan keluarga maupun masyarakat umum. 
Journal of Healthcare Technology and Medicine Vol. 5 No. 2 Oktober 2019

Universitas Ubudiyah Indonesia

e-ISSN : 2615-109X

\section{Target Dan Luaran}

\section{A. Target Instruktusional Umum}

Tujuan dari Pada akhirnya diharapkan masyarakat khususnya di Dusun V Sumbul Lestari, Desa Sumbul, Kabupaten Deli Serdang, dapat menyadari akan bahayanya melakukan kegiatan yang menyebarkan zat - zat berbahaya dari sampah untuk menjaga kesehatan udara di sekitar lingkungan.

\section{B. Target Instruktusional Khusus}

Setelah diberikan penyuluhan langsung kepada masyarakat di Dusun V Sumbul Lestari, Desa Sumbul, Kabupaten Deli Serdang pada 11 Februari 2019, masyarakat akan mampu:

a) Mengerti dan mengetahui pentingnya menjaga kebersihan udara.

b) Mengerti dan mengetahui apa - apa saja yang dapat dilakukan untuk menjaga kebersihan udara.

c) Mengerti pengertian kebersihan lingkungan dan efek yang ditimbulkan apabila tidak menjaga kebersihan lingkungan untuk menanggulangi efek bahan - bahan pencemaran lingkungan tersebut.

d) Mengerti manfaat menjaga kebersihan lingkungan terhadap kesehatan keluarga dan masyarakat

\section{Bentuk Kegiatan}

1. Penyuluhan secara langsung

2. Dialog dan tanya jawab

\section{Tempat Kegiatan}

Dilaksanakan di Dusun V Sumbul Lestari, Desa Sumbul, Kecamatan STM Hilir, Kabupaten Deli Serdang.

\section{E. Waktu Kegiatan}

Kegiatan ini dilaksanakan pada tanggal 6 Juli 2019. 


\section{F. Materi Pokok dalam Kegiatan}

Untuk mencapai tujuan kegiatan diatas, materi untuk penyuluhan disusun dengan sedemikian rupa yang terdiri dari: pengertian pencemaran udara hubungannya dengan pengelolaan sampah yang tidak benar, zat - zat yang dihasilkan dari pembakaran sampah, cara dan manfaat mengelola sampah yang baik dan benar terhadap kesehatan udara di lingkungan dusun.

\section{METODE PELAKSANAAN}

\section{A. Khalayak Sasaran}

Dalam sasaran dari kegiatan ini adalah masyarakat umum di Dusun V Sumbul Lestari, Desa Sumbul, Kabupaten Deli Serdang. Penyuluhan ini dilakukan sesuai dengan aplikasi bidang ilmu kesehatan masyarakat dan/serta adanya dukungan kegiatan gotong royong dari pihak Dusun V Sumbul Lestari, Desa Sumbul, Kabupaten Deli Serdang.

\section{B. Keterkaitan}

Dalam melakukan kegiatan pengabdian masyarakat dalam bentuk penyuluhan ini, bidang ilmu yang dianggap berkaitan didalam ilmu kesehatan masyarakat adalah ilmu perilaku dan promosi kesehatan.

\section{Metode Kegiatan}

Metode kegiatan yang dipakai dalam kegiatan pengabdian masyarakat ini meliputi, penyuluhan secara langsung dikarenakan agar masyarakat dapat lebih mengerti dengan materi yang disampaikan kemudian dilanjutkan dengan sesi diskusi dan tanya jawab untuk menambah ilmu masyarakat tentang pentingnya menanam pohon bagi lingkungan. Tempat: Dusun V Sumbul Lestari, Desa Sumbul, Kecamatan STM Hilir, Kabupaten Deli Serdang.

\section{Rangkuman Materi Terlampir}

\section{Pengertian Umum Pencemaran Udara dan zat - zat pencemar}


Journal of Healthcare Technology and Medicine Vol. 5 No. 2 Oktober 2019

Universitas Ubudiyah Indonesia

e-ISSN : 2615-109X

Masalah pencemaran lingkungan yang terjadi karena masalah pengelolaan sampah bisa menjadi masalah serius di beberapa daerah. Ini dikarenakan pengelolaan sampah yang baik dan benar tidak disosialisakan dengan baik sampai ketingkat masyarakat terendah seperti masyarakat dusun. Akan tetapi untuk mencapai kondisi masyarakat yang hidup sehat dan sejahtera di masa yang akan datang, akan sangat diperlukan adanya lingkungan permukiman yang sehat.

Mengelola sampah dengan baik dan benar harus dimulai dari sampah rumah tangga ini. Ini dikarenakan, umumnya sampah - sampah rumah tangga tersebut apabila tidak dikelola dengan baik, dapat menumpuk dan menyebabkan terjadinya kerusakan lingkungan dan bahkan menjadi penyebab pencemaran udara karena banyak dari sampah rumah tangga tersebut mengandung bahan - bahan berbahaya yang dapat merusak kesehatan udara.

Polusi udara dapat diklasifikasikan menjadi partikel halus seperti debu, uap, kabut dan asap, bahan polutan berbentuk gas seperti ( $\mathrm{CO} 2$ dan $\mathrm{CO})$, dan juga bau. Partikel halus bisa dapat dibagi lagi sesuai dengan kepadatan partikel yaitu PM10 dan PM2,5. Dimana partikel halus ini termasuk dapat mempengaruhi kesehatan udara dan dapat mempengaruhi kesehatan manusia bahkan sampai merusak jaringan paru - paru pada manusia.

Untuk bahan polutan berbentuk gas seperti SO2, CO, CO2 dan berbagai macam bahan Nitrogen seperti NO2 apabila terlalu banyak disebarkan ke udara bisa berdampak langsung terhadap lingkungan yaitu terhadap pemanasan global. Ini dikarenakan gas - gas tersebut dapat merusak lapisan ozon secara langsung.

Salah satu pengelolaan sampah rumah tangga yang sangat banyak dilakukan adalah pembakaran sampah. Seperti diketahui, masyarakat yang tinggal di daerah dusun sangat sering melakukan pembakaran sampah. Metode pembakaran sampah ini sangat tidak dianjurkan untuk dipergunakan sebagai sarana menghancurkan sampah. Ini dikarenakan, membakar sampah itu sendiri dapat memberikan efek negatif terhadap lingkungan dengan menyebarkan gas $\mathrm{CO} 2$ dan $\mathrm{CO}$ ke udara yang berdampak langsung terhadap pemanasan global. Oleh Pemerintah Ibu Kota sendiri, pembakaran sampah ini sudah dilarang melalui Peraturan Pemerintah Daerah no. 25 tahun 2005 yang melarang pembakaran sampah baik di manapun. 
Journal of Healthcare Technology and Medicine Vol. 5 No. 2 Oktober 2019

Universitas Ubudiyah Indonesia

e-ISSN : 2615-109X

Disamping itu, masih bisa dilihat bahwa di daerah dusun sarana dan prasarana pembuangan sampah kurang memadai. Ini dapat menyebabkan kumpulan sampah yang menggunung di beberapa titik di dusun tersebut dan menyebabkan adanya polusi udara yang baru yaitu polusi bau. Ini dapat menyebabkan tumbuhnya bibit - bibit penyakit seperti malaria dan penyakit lainnya yang merusak kualitas hidup masyarakat di dusun tersebut.

Beberapa cara yang bisa dilakukan oleh masyarakat pada umumnya dalam rangka pengelolaan sampah adalah sebagai berikut:

- Memastikan bahwa tersedia nya sarana - sarana pembuangan sampah yang lengkap dirumah.

- Memastikan bahwa perangkat pemerintah setempat menyediakan sarana tempat pembuangan akhir yang memadai didaerahnya.

- Memastikan bahwa pemerintah setempat menyediakan sarana bagi masyarakat untuk mengumpulkan sampah rumah tangga mereka ke tempat pembuangan akhir.

- Memastikan tidak dipergunakan cara - cara seperti pembakaran sampah untuk memusnahkan sampah - sampah rumah tangga.

\section{Hasil Dan Luaran Yang Dicapai}

Hasil dicapai dari kegiatan penyuluhan ini adalah untuk menjadikan masyarakat peduli dan mengerti tentang pentingnya mengelola sampah di sekitar rumah dan juga lingkungan sekitar nya. Dimana ini dipertunjukkan dengan antusiasme masyarakat dalam mengikuti kegiatan penyuluhan ini. Di penyuluhan ini, masyarakat mengerti dan memahami bahwa pengelolaan sampah tidak hanya untuk menjaga kebersihan lingkungannya, akan tetapi juga dapat turut andil dalam menjaga kebersihan udara agar terhindar dari pencemaran udara.

Dimana hasil dari penyuluhan adalah untuk meneruskan hasil - hasil penyuluhan di desa ini sebelumnya dengan mempunyai target jangka panjang yaitu untuk membuat desa ini mampu untuk menjadi sebuah Desa Mandiri. Untuk menjadi sebuah desa yang mandiri, masyarakat juga harus mempunyai semangat untuk membangun dan menjaga daerah nya supaya terhindar dari semua hal yang dapat memberikan hal negatif terhadap daerah tersebut seperti zat - zat emisi berbahaya yang dapat dihasilkan dengan pengelolaan 
Journal of Healthcare Technology and Medicine Vol. 5 No. 2 Oktober 2019

Universitas Ubudiyah Indonesia

e-ISSN : 2615-109X

sampah yang tidak benar. Ini dapat dimulai dari penyuluhan kepada masyarakat tentang bahaya zat - zat emisi yang berbahaya yang dibuang ke udara supaya masyarakat dapat terhindar dari bahaya pencemaran udara. Hasil yang sudah ditunjukkan dari penyuluhan ini adalah dengan antusiasnya masyarakat mengikuti kegiatan gotong - royong yang diadakan bersamaan dengan kegiatan penyuluhan ini.

\section{Rencana Tahapan Berikutnya}

Dengan meningan tujuan jangka panjang dari kegiatan penyuluhan ini yaitu menjadikan Desa Sumbul sebagai desa yang mandiri, maka untuk tahap berikutnya akan dilakukan lagi penyuluhan - penyuluhan yang berkenaan dengan topik - topik yang dapat membantu daerah tersebut menjadi desa yang mandiri dengan masyarakat menyadari hal hal apa saja yang menjadi kebutuhan agar menjadikan daerah tersebut mandiri. Ini akan menjadikan Desa Sumbul menjadi salah satu daerah yang menjadi binaan tim penyuluh dalam rangka menjadikan Desa Sumbul menjadi desa mandiri.

\section{KESIMPULAN}

Laporan kegiatan pengabdian masyarakat tentang Penyuluhan Masyarakat Tentang Pentingnya Mengelola Sampah yang baik dan benar bagi lingkungan yang dilakukan di Dusun V Sumbul Lestari, Desa Sumbul, Kabupaten Deli Serdang dapat disimpulkan sebagai berikut:

1. Kegiatan penyuluhan telah terlaksana dengan lancar dan sesuai dengan tujuan dan rencana

2. Kegiatan ini mendapat sambutan yang baik dari Masyarakat Kampung Sejahtera ditunjukkan dengan meningkatnya masyarakat yang berpartisipasi dalam kegiatan gotong royong yang dilaksanakan oleh perangkat Dusun V.

\section{SARAN}

1. Perlunya kegiatan penyuluhan dilaksanakan di lingkungan-lingkungan lain terlebih ditempat masyarakat dengan tingkat ekonomi kecil untuk memberikan pengertian lebih kepada mereka tentang pentingnya mengelola sampah bagi lingkungan. 
Journal of Healthcare Technology and Medicine Vol. 5 No. 2 Oktober 2019

Universitas Ubudiyah Indonesia

e-ISSN : 2615-109X

2. Hasil kegiatan masih perlu dikembangkan lebih lanjut untuk meningkatkan tingkat partisipasi kegiatan gotong royong yang akan dilaksanakan selanjutnya.

\section{DAFTAR PUSTAKA}

Aprilia, A., Tezuka, T. and Spaargare, G. (2012). Household Solid Waste Management in Jakarta, Indonesia: A Socio-Economic Evaluation. Waste Management - An Integrated Vision.

Andreasi Bassi, S., Christensen, T. and Damgaard, A. (2017). Environmental performance of household waste management in Europe - An example of 7 countries. Waste Management, 69, pp.545-557.

Wadehra, S. and Mishra, A. (2019). Managing waste at the household level: Field evidence from Delhi. [online] New Delhi: International Growth Center, pp.2-5. Available at: https://www.theigc.org/wp-content/uploads/2017/10/Wadehra-et-al-Finalreport_cover.pdf 